\title{
Interceptive Orthodontics for Correction of Ectopically Erupted Permanent Maxillary Central Incisor Through Abnormally Thick Labial Frenum: An Unusual Case Report
}

\author{
Ishika Garg' Shruti Jha' Anu Kadian' Ritu Namdev Arun Kumar' \\ 'Department of Pedodontics and Preventive Dentistry, PGIDS, Rohtak, \\ Haryana, India \\ Address for correspondence: Ishika Garg, Department of \\ Pedodontics and Preventive Dentistry, PGIDS, Rohtak, Haryana \\ 124001, India \\ E-mail: gargishika1993@gmail.com
}

\begin{abstract}
The intimate relation between the apices of primary incisors and their successors explains the disruptive effect of intrusion injuries on permanent teeth, one of which is the disturbance of eruption. The ectopic eruption is a deviation of the tooth from its normal erupting path, making it to erupt in an abnormal position. The ectopic eruption has got multi-factorial etiology, and its management depends on the correction of the established etiological factor. The present case report describes correction of ectopically erupted permanent maxillary right central incisor encased within thickened maxillary labial frenum by orthodontic repositioning.
\end{abstract}

Keywords: Ectopic eruption, intrusive luxation, malocclusion, orthodontic repositioning, thickened labial frenum

\section{Introduction}

Ectopic eruption refers to a developmental disturbance characterized by eruption of a tooth in a position away from its normal position in the dental arch.[1] The prevalence of ectopic eruption of permanent teeth is approximately $5.6 \%[2,3]$ and the majority of these are maxillary and mandibular central incisors accounting for more than half of the total frequency.[4]

A rare developmental anomaly, the ectopic eruption has several theories attributed to explain its cause of occurrence, including trauma, infection, cyst, presence of supernumerary tooth, and crowded dentition.[5]
Intrusive trauma to a primary tooth is also one of the significant causes of the permanent successors' ectopic eruption.[6] Ectopic eruptions may be seen in many maxillofacial skeleton regions, including palate, maxillary sinus, condyle, orbit, or even through the skin.[7]

The management of ectopic eruption depends on the etiology, position, patient's esthetic concern, and accommodability of the tooth into an acceptable position within the arch. Correction of established etiological factors followed by an orthodontic repositioning of the tooth, if required, is the most desirable and acceptable treatment option for ectopically erupted permanent teeth.

How to cite this article: Garg I, Jha S, Kadian A, Namdev R, Kumar A. Interceptive Orthodontics for Correction of Ectopically Erupted Permanent Maxillary Central Incisor Through Abnormally Thick Labial Frenum: An Unusual Case Report. J Pediatr Dent 2020;6(2):57-60 
Ectopically positioned permanent maxillary central incisor is a frequent cause of developing dental malocclusion and often requires interceptive orthodontic intervention to bring the tooth into its correct position. Interceptive procedures should be undertaken as soon as sufficient permanent teeth have erupted and adequate co-operation from the child is obtained to accept the various steps of the treatment procedure.[3]

The present case report describes interceptive management of ectopically erupted permanent maxillary central incisor that was almost completely encased within the labial frenum.

\section{Case Presentation}

A systemically healthy 13-year-old male patient reported to the Department of Pedodontics and Preventive Dentistry, PGIDS, Rohtak, Haryana, with the chief complaint of an unerupted upper front tooth. Past dental history revealed intrusive trauma to the upper right primary incisor at the age of 3 years. On intra-oral examination, the ectopic eruption of the right permanent maxillary central incisor was noted, which was almost completely enclosed within the maxillary labial frenum with only the distal incisal tip of the tooth visible intra-orally (Fig. 1). Intraoral periapical examination revealed complete root formation in respect to 11 (Fig. 2). The patient also reported a history of frequent ulceration and irritation of the upper labial mucosa due to impingement of the tooth's sharp incisal tip on the soft mucosal tissue. The tooth was encased in the frenum to such an extent that it could only be visualized on the patient's upper lip's upward and outward stretching. Moreover, it caused the migration of other incisors resulting in loss of space for the ectopic tooth.

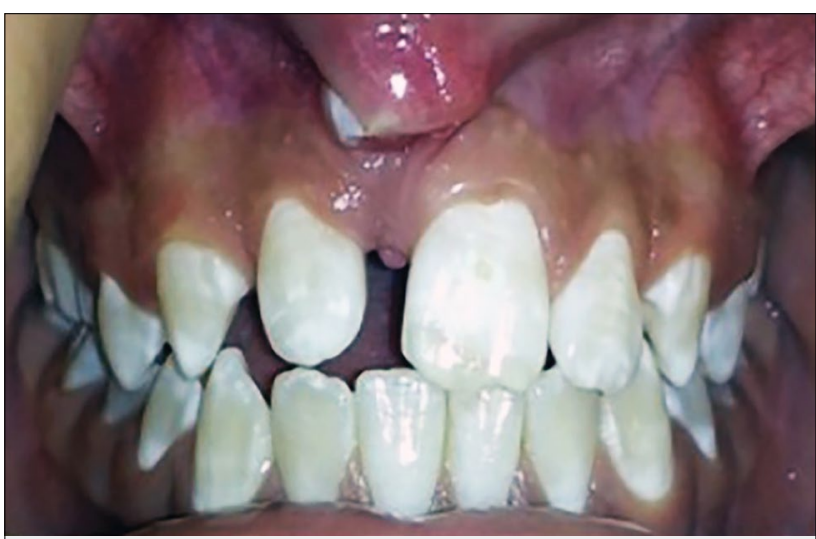

Figure 1. Ectopically erupted right permanent maxillary central incisor encased within the maxillary labial frenum



The initial treatment planning comprised of three stages: Regaining space for ectopically erupted central incisor; surgical excision of hypertrophied labial frenum and exposure of crown of right maxillary incisor concurrently; and orthodontic alignment of the concerned tooth. Semi-fixed orthodontic treatment was initiated, and a coil spring was placed between the maxillary left central incisor and right lateral incisor to regain the space for accommodating ectopically erupted central incisor. Within 3 weeks, while the necessary space was regained, simultaneous movement of the right maxillary central incisor in the occlusal direction also took place dramatically in the regained space ensuing us to drop the second stage of treatment and proceed directly towards the final stage.

When the lost space was recovered completely, the ectopic incisor was guided into full occlusion within the arch by inserting overlay Ni-Ti wire sequentially (Fig. 3). After six months, when the incisor was adequately aligned in the arch, fixed orthodontic appliances were removed, following which bonded lingual retention was given using Ribbond (Fig. 4).

\section{Discussion}

Intrusive luxation, which causes displacement of the tooth in the alveolus, is the most common trauma dur- 

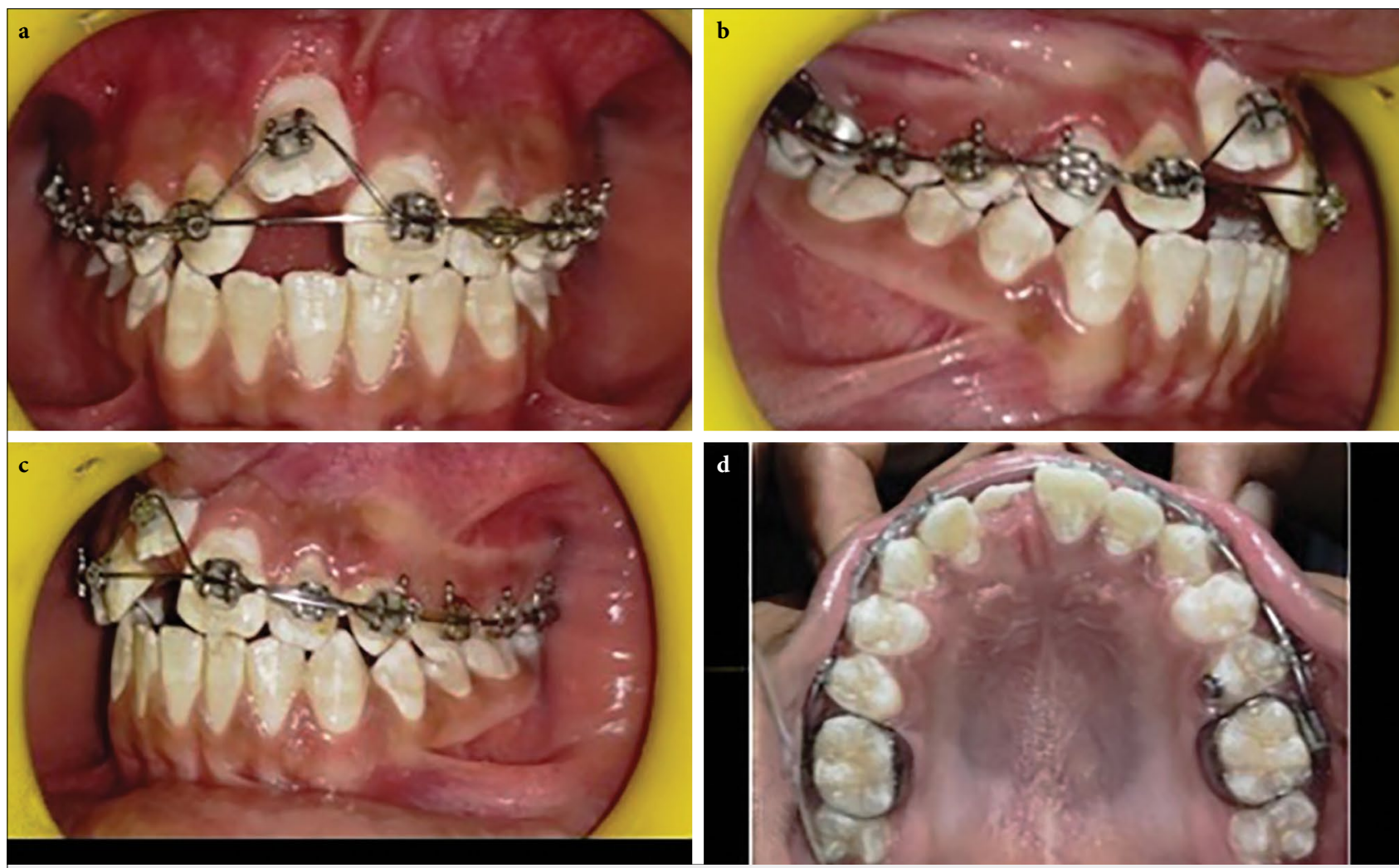

Figure 3. Central incisor engaged in orthodontic wire to guide its alignment (a) Frontal view (b) Right lateral view (c) Left lateral view (d) Occlusal view
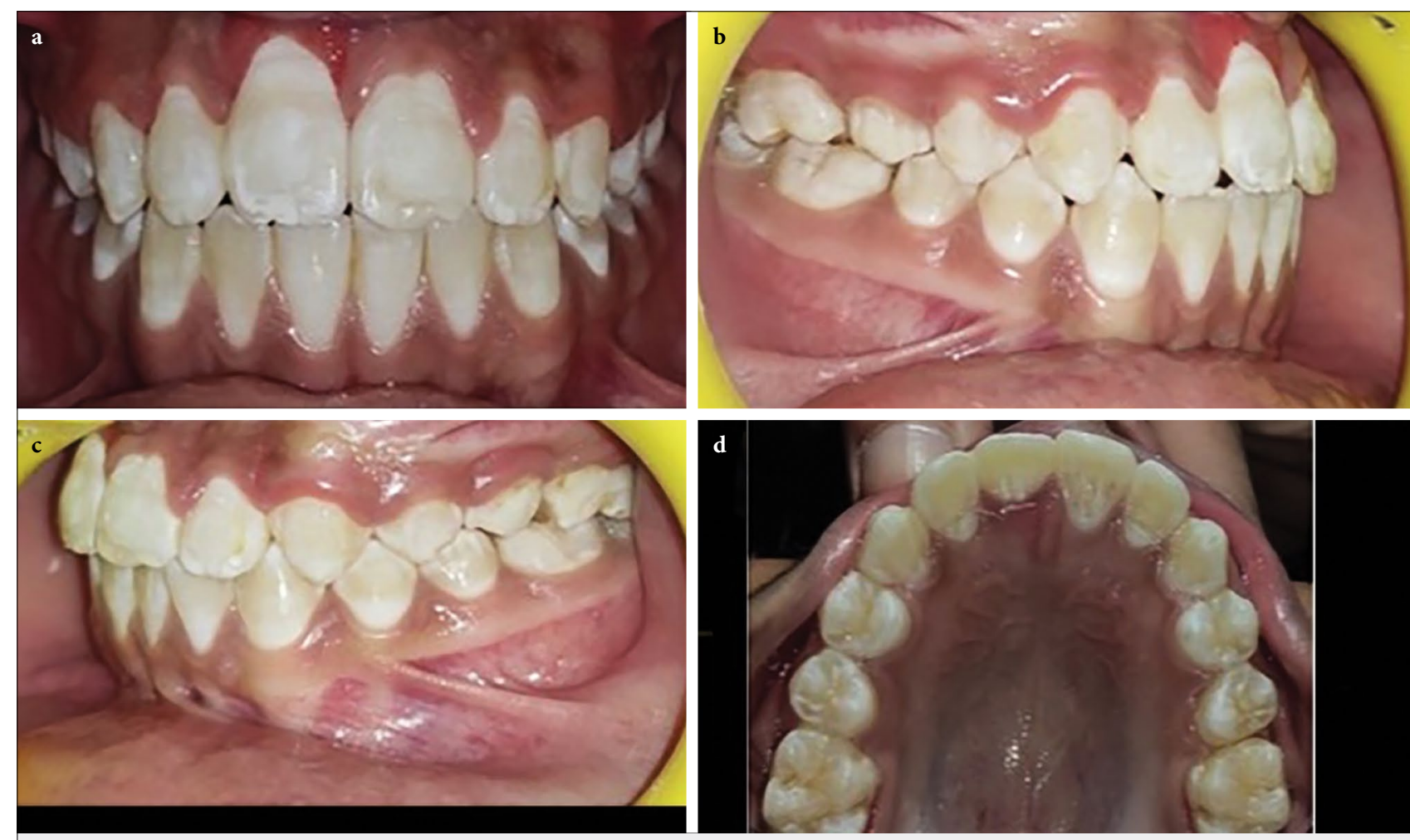

Figure 4. Well-aligned right permanent maxillary central incisor in the arch (a) Frontal view (b) Right lateral view (c) Left lateral view (d) Occlusal view 
ing early childhood constituting $4.4 \%-22 \%$ of traumatic injuries in the primary dentition. It is mostly encountered in children between 1 and 3 years of age.[8] Primary maxillary central incisors are the most commonly affected teeth. $[9,10]$

An intruded primary tooth may result in developmental disturbances of its successor permanent tooth as a result of the close proximity of the developing permanent tooth germ to the primary root apex.[11] Ectopic eruption of the permanent tooth in one such developmental disturbance caused by the physical displacement of the permanent germ, the lack of eruption guidance by the previously traumatized/premature loss of primary incisor, or both.[12]

The present case report describes a similar case in which prior intrusive luxation of primary tooth led to the ectopic eruption of the corresponding permanent maxillary central incisor at vestibular depth encasing the labial frenum. A multidisciplinary approach involving surgical exposure, orthodontic treatment, and sometimes prosthodontic rehabilitation is required to treat such an ectopically erupted tooth.

Gugnani et al,[13] presented a similar case report in which an ectopically erupted central incisor encased within an abnormally thickened labial frenum was orthodontically realigned following a frenectomy. However, in the present case, frenectomy though initially planned was not required because of dramatic occlusal movement of the ectopic tooth after regaining space, thus preventing permanent scar tissue formation common after frenectomy procedure. The space was regained using an open coil spring based on the findings of the study by von Fraunhofer et al,[14] who stated that coil springs deliver a relatively constant force over a range and up to $7 \mathrm{~mm}$ tooth movement can be achieved.

Fixed orthodontic treatment was continued to achieve proper alignment of the tooth resulting in good esthetic and functional rehabilitation.

\section{Conclusion}

A proper history and meticulous clinical oral examination are a prerequisite in patients with developmental anomalies, especially ectopic disturbances, to make a correct diagnosis and plan the most suitable treatment for an individual patient to intercept the devel- oping malocclusion and avoid any further damage to the dentition.

\section{Financial Disclosure: Nil. \\ Conflict of Interest: None declared.}

\section{References}

1. Mattos BSC, Carvalho JCM, Matusita M, Pinhiero Alves APP. Tooth transposition literature review and a clinical case. Braz J Oral Sci 2006;5(16):953-957

2. Doruk C, Babacan H, Bicakci A. Correction of a mandibular lateral incisor-canine transposition. Am J Orthod Dentofacial Orthoped 2006;129(1):65-72

3. Shapira Y, Kuftinec MM. Infrabony migration of impacted teeth. Angle Orthod 2003;73(6):738-743

4. Kumagai E, Sai S, Nozaka K, Yamada S, Amari E. Clinical study of ectopic eruption of permanent incisors and first molars. Shoni Shikagaku Zasshi 1989;27:30-40

5. Portela MB, Sanchez AL, Gleiser R. Bilateral distal ectopic eruption of the permanent mandibular central incisors: A case report. Quintessence Int 2003;34:131-134

6. Manuja N, Nagpal R, Singh M, Chaudhary S. Management of delayed eruption of permanent maxillary incisor associated with the presence of supernumerary teeth: A case report. Int J Clin Pediatr Dent 2011;4:255-259

7. Goh YH. Ectopic eruption of maxillary molar tooth - An unusual cause of recurrent sinusitis. Singapore Med J 2001;42:80-81

8. Altunsoy M, Bilgin MS. Management of an intruded primary central incisor with a natural crown under general anesthesia. Eur J Dent 2014;8(2):265-268

9. Diab M, elBadrawy HE. Intrusion injuries of primary incisors. Part III: Effects on the permanent successors. Quintessence Int 2000;31:377-384

10. Arikan V, Sari S, Sonmez H. The prevalence and treatment outcomes of primary tooth injuries. Eur J Dent 2010;4(4):447-453

11. Andreasen JO. Injuries to the developing teeth. In: Andreasen JO, Andreasen FM, editors. Textbook and color atlas of traumatic injuries to the teeth. Copenhagen: Munksgaard; 1994. p. 457-494.

12. Brin I, Ben-Bassat Y, Zilberman Y, Fuks A. Effect of trauma to the primary incisors on the alignment of their permanent successors in Israelis. Community Dent Oral Epidemiol 1988;16(2):104-108

13. Gugnani N, Pandit IK, Gupta M, Gugnani S, Vishnoi A, Sabharwal O, et al. Ectopic eruption of maxillary central incisor through abnormally thickened labial frenum: An unusual presentation. J Indian Soc Pedod Prev Dent 2017;35:94-97

14. von Fraunhofer JA, Bonds PW, Johnson BE. Force generation by orthodontic coil springs. Angle Orthod 1993;63:145-148 